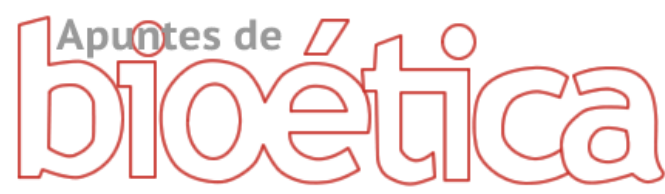

https://doi.org/10.35383/apuntes.v1i1.198

\title{
Familia: Hábitat natural del ser humano - estructura base de una verdadera ecología humana
}

Karin Anell Oviedo Valencia ${ }^{1}$, Rubén Gilberto Tarazona Reyes ${ }^{2}$

\section{INFORMACIÓN DEL ARTÍCULO RESUMEN}

Recibido el 29 de setiembre de 2018

Aceptado el 21 de noviembre de 2018

\section{Palabras claves:}

Ecología Humana

Familia

Persona

Matrimonio.
Entendemos como "hábitat natural" el ambiente o espacio que cuenta con las condiciones físicas y biológicas mínimas requeridas para la supervivencia de una especie. Si un determinado hábitat se ve alterado o vulnerado por algún agente externo o interno, la especie que lo habita corre el riesgo de extinguirse. Así como todas las especies en nuestro planeta, el ser humano, también tiene la necesidad de contar con un hábitat ecológico natural adecuado, que le permita vivir conforme a su condición de persona y alcanzar su máximo desarrollo de manera integral. En este sentido, la familia representa un papel fundamental en la vida de cada individuo; es en la familia donde el hombre aprende a ser "persona", aprende a amar, a valorarse a sí mismo y a sus semejantes. La familia es el primer lugar que sirve al hombre como refugio, donde se siente protegido, amado, respetado y aceptado, independientemente de sus logros o de sus fracasos. De acuerdo con lo expresado, el propósito del presente trabajo es destacar la importancia de la familia como hábitat natural de la persona humana, así como la necesidad de su preservación y conservación, dado el papel fundamental que desempeña en la formación de los seres humanos, reforzando el concepto de familia como estructura base de una verdadera ecología humana.

${ }^{1}$ Ingeniera geógrafa por la Universidad Nacional Federico Villareal. Jefa del área de sistemas de información geográfica (GIS) de la Compañía Operadora de gas del Amazonas (COGA). Maestra en Personal Matrimonio y Familia. Email: koviedo@outlook.com. ORCID: https://orcid.org/0000-0002-9592-2838

${ }^{2}$ Ingeniero forestal por la Universidad Nacional Agraria La Molina. Gerente de operaciones en DOMUS Consultorio Ambiental SAC. Maestro en Personal Matrimonio y Familia. Email: ruben.tarazona@gmial.com. ORCID: https://orcid.org/0000-0002-5192-8808 


\section{Family: natural habitat of the human being - basic structure of a true human ecology}

ABSTRACT
$\begin{aligned} & \text { Keywords: } \\ & \text { Human Ecology } \\ & \text { Family } \\ & \text { Person, } \\ & \text { Marriage }\end{aligned}$
We understand as "natural habitat" the environmental or space that has the
minimum physical and biological conditions required for the survival of a
specie. If a particular habitat is altered or compromised by any external or
internal agent, the specie that inhabits could be in risk of extinction. Like all
species on our planet, humans, also has the need for adequate natural
ecological habitat, which allows them to live according to their human
condition and reach their maximum development holistically. In this sense,
the family plays a key role in the life of every individual, is in the family
where the man learns to be a "person", and learn to love and value
themselves and their fellows. The family is the first place that serves the
man as a refuge, where you feel protected, loved, respected and accepted,
regardless of their achievements or failures. According to the statement, the
purpose of this paper is to highlight the importance of the family as the
natural habitat of the human being and the necessity for its preservation
and conservation, due the key role of the family in the formation of human
being, also reinforce the concept of family as the basic structure of a true
human ecology.

\section{Introducción}

La ecología humana, es un concepto relativamente nuevo, que viene siendo estudiado desde distintos enfoques o perspectivas. Muchos especialistas, entre ellos podemos mencionar a G. Marten y C. Bernis, definen la ecología humana como el estudio de las relaciones o interacción del hombre con su entorno natural o con el medio ambiente que lo rodea. (Marten \& Bernis, 2001). Sin embargo, esta definición es muy limitada y no logra abarcar en su totalidad el alcance de la verdadera ecología humana tal como la plantea Juan Pablo II en su Encíclica Centesimus Annus. En esta encíclica Juan Pablo II (1991) presenta una perspectiva de Ecología Humana enfocada en el hombre y su necesidad de contar con un hábitat ecológico personal. Así mismo, nos muestra a la familia de fundación matrimonial como el hábitat natural donde el hombre aprende que significa amar y ser amado y encuentra el ambiente necesario para lograr su desarrollo integral

En el mundo actual el medio ambiente y la ecología son temas prioritarios, nos encontramos frente a una gran preocupación por la conservación del medio ambiente, se han desarrollado y planteado conceptos relacionados con "ecología" orientados a preservar los recursos naturales, especies en peligro de extinción, recuperación de hábitats, etc. Los gobiernos y organizaciones internacionales favorecen la investigación e implementación de programas y planes de protección al medio ambiente. No obstante, estos conceptos olvidan 
al actor principal que es el hombre, no se considera dentro de los planes de protección y preservación del medio ambiente la protección y preservación de la naturaleza humana y por consiguiente de la familia, que es la primera estructura fundamental a favor de la ecología humana (Juan Pablo II, 1991).

Por el contrario, en la actualidad existen diversas teorías (el utilitarismo, el individualismo, el relativismo), leyes y tendencias o ideologías (la ideología de género) que pretenden desvirtuar el verdadero significado de familia, reduciéndolo a un capricho o deseo de satisfacción personal.

En relación a la preocupante situación de la familia actual, Gómez (2012) refiere:

Hay muy poca preocupación por los niños. Esto es triste, porque ellos serán los "sujetos" de todos nuestros experimentos sociales. Ellos llevarán las consecuencias de todas nuestras nuevas maneras de definir lo que significa estar "casado" o ser "padres" o ser una "familia. (pág. 1)

Por otro lado, existe también una acentuada crisis en las familias que se ven afectadas por temas morales (infidelidad, drogas, alcoholismo, hedonismo, relativismo moral, entre otros). Esto ocasiona rupturas familiares en donde cada uno de los protagonistas busca su propia satisfacción, necesidad de "realización" o "felicidad personal" olvidándose de sus hijos y las consecuencias que en ellos puede traer su comportamiento egoísta. Los niños y adolescentes se ven obligados a crecer en medio de una familia fracturada que no les brinda el hábitat adecuado y necesario para su desarrollo integral como persona humana.

Un estudio realizado por el Social Trend Institute (2007) ,presenta como una de sus principales conclusiones: "La importancia del matrimonio en la sociedad actual, en la preservación del bien común, así como en el fomento del bienestar de los hijos y por ende en la preservación de la familia y la persona humana" (pág. 11).

C. Conen (2014) al respecto enfatiza la necesidad en el ser humano de contar con un hábitat ecológico personal adecuado para vivir conforme con su condición, este hábitat está dado por la familia. Es en el seno familiar donde el ser humano se siente valorado de manera incondicional y donde recibe la protección física, afectiva y moral necesaria para su desarrollo como persona humana.

En medio de la cambiante sociedad actual, que cada vez vulnera más a la familia de fundación matrimonial, pretendiendo reducir su papel fundamental en la formación de las personas a un simple papel reproductor, es que nos planteamos las siguientes interrogantes ¿Cuál es la importancia de la familia como hábitat natural para el desarrollo integral de la persona humana acorde a su dignidad y singularidad?, ¿Por qué es importante preservar y conservar a la familia como estructura fundamental de una verdadera ecología Humana?.

A fin de responder a las interrogantes planteadas, presentamos un análisis de la importancia de la familia como hábitat natural para el desarrollo de la persona, reconociendo al ser humano como un ser único e irrepetible, pero a la vez social, que necesita relacionarse con sus semejantes para poder reconocerse como persona en su singularidad y dignidad, en este proceso de formación de la persona humana, la familia juega un rol fundamental. Para finalizar y como complemento de lo antes mencionado, destacamos la importancia de salvaguardar y preservar a la familia como hábitat natural para la adecuada formación y desarrollo de la persona humana, así como el 
papel fundamental que desempeña como institución natural de la sociedad, y la importancia del matrimonio y la familia en la revalorización de la dignidad del hombre.

\section{Metodología}

La investigación ha sido realizada en base a una investigación del tipo cualitativa (análisis documental), la cual se aplica principalmente en el ámbito de las ciencias sociales, y está referida al análisis e interpretación de fuentes bibliográficas.

Dentro de este tipo de investigación específicamente nos centramos en la investigación-acción, que persigue encontrar soluciones a problemas en la sociedad (grupo, comunidad u organización).

Para el desarrollo de la investigación se utilizó el análisis y la síntesis como procedimientos; y como técnicas, la observación indirecta y el fichaje con fichas de contenido (fichas textuales y fichas de paráfrasis). Así mismo se estableció una secuencia de pasos y actividades que nos brindó un orden lógico para el correcto desarrollo de la misma.

\section{Resultados, análisis y discusión}

\section{La familia como hábitat natural para el desarrollo de la persona humana}

El ser humano es un ser único e irrepetible, pero no es un ser aislado, el ser humano es un ser que necesita relacionarse con los demás para poder reconocerse como persona. La absoluta necesidad de cuidados y atención que requiere un ser humano al llegar al mundo para sobrevivir debería servirnos de muestra para entender que no podemos alcanzar nuestro máximo desarrollo de manera aislada, necesitamos por consiguiente un hábitat natural adecuado para lograr ese desarrollo. En este sentido C. Conen (2014) señala que "existe la necesidad en el ser humano de contar con un hábitat ecológico personal adecuado para vivir conforme con su condición, en esto se basa la ecología humana".

Una auténtica ecología humana busca lograr un ambiente donde el ser humano pueda desarrollarse de manera integral. En ese sentido, Juan Pablo II (1991) identifica a la familia como la estructura base de la ecología humana. Así mismo C. Conen (2012) señala:

\footnotetext{
El ser humano necesita además de un hábitat físico adecuado para vivir, un ámbito personal ecológico que desarrolle la capacidad para el encuentro, la unidad y la vida comunitaria. El ser humano necesita un hábitat donde reciba trato personal adecuado a su dignidad, sentido profundo de pertenencia e identidad, valoración o amor incondicional y ese hábitat es la familia. (pág. 17)
}

La importancia de la familia como hábitat natural de la persona humana se centra justamente en que es la familia el primer lugar que sirve al hombre como refugio, donde se siente protegido, amado, respetado, independientemente de sus logros o de sus fracasos. "La familia es el hábitat donde la persona nace, crece, vive y muere como persona humana, porque es el hábitat donde el hombre puede sentirse valorado por sí mismo e incondicionalmente" (Conen, 2012, pág. 28)

M. Lacalle, hace también referencia a la importancia de la familia en el desarrollo integral de la persona humana, resalta la necesidad de toda persona de sentirse valorada y querida, especialmente los niños, quienes forman una idea de su propia persona en función a los mensajes explícitos e implícitos que reciben de sus padres. Los niños necesitan el cariño de sus 
padres para poder desarrollar una personalidad equilibrada. Es en la familia donde los niños encuentran protección, apoyo incondicional, ternura, comprensión, confianza, seguridad, etc. Todo ello necesario para su desarrollo integral (Lacalle, 2015).

Así mimo M. Lacalle (2015) utiliza argumentos bastante válidos que nos permiten reforzar el concepto de familia como hábitat natural de la persona:

Un niño que ha nacido en un entorno familiar que le ha brindado amor sin condiciones independiente de sus éxitos y de sus fracasos, será capaz de relacionarse con los demás desde la seguridad y desde el respeto, pues será a su vez capaz de amar a los demás gratuitamente. Esto es así porque una adecuada comunicación y convivencia con los demás solo puede darse desde la propia seguridad. El que está seguro de sí mismo y es consciente de su propio valor y de su propia dignidad como ser humano, es capaz de ver a los demás como personas igualmente valiosas y dignas. $\mathrm{Y}$, por consiguiente, puede establecer con ellas una relación interpersonal basada en el respeto y en el amor. (pág. 236)

En este sentido, podemos afirmar que el contar con un hábitat natural adecuado para su desarrollo integral como es la familia, tiene una gran repercusión en la formación del ser humano y en su manera de enfrentar la vida.

Por otro lado, Juan Pablo II en su Exhortación Apostólica Familiaris Consortio, resalta la misión de la familia de ser comunidad de vida y amor, así mismo exhorta a las familias a cumplir con su misión de custodiar, revelar y comunicar el amor. También, hace mención de los cometidos generales de la familia, resultado del sínodo de los obispos celebrado en Roma en 1980: 1) formación de una comunidad de personas; 2) servicio a la vida; 3) participación en el desarrollo de la sociedad; 4) participación en la vida y misión de la Iglesia (Juan Pablo II, 1981).

Así mismo el Papa Francisco en su Exhortación Apostólica Amoris Laetitia (2016), señala que:

La familia es el sujeto protagonista de una ecología integral, porque es el sujeto social primario, que contiene en su seno los dos principios-base de la civilización humana sobre la tierra: el principio de comunión y el principio de fecundidad.

El mensaje de Juan Pablo II y el Papa Francisco, refuerza aún más el significado de familia como hábitat natural para el desarrollo del ser humano, al identificar a la familia como una comunidad de vida y amor, con una participación activa en el desarrollo de la sociedad.

\section{Revalorización de la dignidad del hombre a través de la familia}

La dignidad de la persona es una cualidad de la que ha sido revestido el ser humano por el simple hecho de pertenecer a la especie humana, es decir por el simple hecho de ser persona y por consiguiente tiene derecho también a una vida digna.

Benedicto XVI en su homilía con motivo del $\checkmark$ Encuentro Mundial de las Familias (2006) resalta la importancia de la familia de fundación matrimonial como el ámbito ideal donde el hombre puede nacer, crecer y desarrollarse con dignidad:

Ningún hombre se ha dado el ser a sí mismo ni ha adquirido por sí solo los conocimientos elementales para la vida. Todos hemos recibido de otros la vida y las verdades básicas para la misma, y estamos llamados a alcanzar 
la perfección en relación y comunión amorosa con los demás. La familia, fundada en el matrimonio indisoluble entre un hombre y una mujer, expresa esta dimensión relacional, filial y comunitaria, y es el ámbito donde el hombre puede nacer con dignidad, crecer y desarrollarse de un modo integral.

No obstante, en la actualidad la familia debe enfrentar múltiples factores que la afectan y que por consiguiente afectan la dignidad de la persona humana. En la sociedad de hoy se pretende aislar a la persona individualizando sus derechos y deberes, pretendiendo reducir el rol de la familia a un rol simplemente reproductor.

Al respecto C. Conen (2012) menciona que no basta hoy con reconocer los derechos fundamentales al hombre de manera aislada o individualizada, es decir derechos de los niños, derechos de los ancianos, derechos de los adolescentes, derechos de la mujer, etc. Es necesario reconocer los derechos fundamentales de la persona humana tomando en cuenta la realidad natural del hombre y la mujer, en cuanto personas, no se trata de individuos aislados, por el contrario hombre y mujer somos seres familiares, necesitamos de la otra persona para reconocer nuestra propia identidad en cuanto que soy hijo, soy padre, soy hermano, soy esposo, etc.

El reconocimiento pleno de estos derechos es de suma importancia para revalorizar la dignidad de la persona humana, es necesario reconocer a la familia de fundación matrimonial su verdadera identidad y dignidad ante la sociedad.

En su Encíclica Centesimus Annus Juan Pablo II (1991) nos dice:

Hay que volver a considerar la familia como el santuario de la vida. En efecto, es sagrada: es el ámbito donde la vida, don de Dios, puede ser acogida y protegida de manera adecuada contra los múltiples ataques a que está expuesta, y puede desarrollarse según las exigencias de un auténtico crecimiento humano. Contra la llamada cultura de la muerte, la familia constituye la sede de la cultura de la vida. (pág. 39)

Así mismo, Juan Pablo II (1981) en su exhortación apostólica Familiaris Consortio menciona:

La familia, en cuanto es y debe ser siempre comunión y comunidad de personas, encuentra en el amor la fuente y el estímulo incesante para acoger, respetar y promover a cada uno de sus miembros en la altísima dignidad de personas. (pág. 22)

Juan Pablo II (1981) resalta también la capacidad de la familia de enfrentar a una sociedad despersonalizada y masificada, inhumana y deshumanizadora. La familia es capaz aún en situaciones adversas (alcoholismo, drogas, etc.) de levantar al hombre y recordarle su dignidad personal para insertarlo nuevamente en la sociedad reconociendo su unicidad e irrepetibilidad.

\section{La Familia: Institución Natural de la Sociedad}

La familia es una institución natural de la sociedad, más aún podemos afirmar que la familia es la célula básica de la sociedad, no solo por su función procreadora, sino por el papel preponderante que juega en la formación de las personas. Como hemos venido repitiendo en los apartados previos, la familia es el hábitat natural óptimo para el correcto desarrollo del ser humano.

Juan Pablo II (1981) en su exhortación apostólica Familiaris Consortio, nos presenta argumentos valiosos que permiten identificar a 
la familia como institución natural de la sociedad:

La familia constituye el lugar natural y el instrumento más eficaz de humanización y de personalización de la sociedad: colabora de manera original y profunda en la construcción del mundo, haciendo posible una vida propiamente humana, en particular custodiando y transmitiendo las virtudes y los «valores». (pág. 43)

Por su parte, M. Lacalle (2015) define a la familia como eje fundamental de la sociedad, tanto por su apertura a la vida, como porque es en el seno familiar donde el ser humano recibe la formación y fortaleza necesarias para enfrentar su propia vida:

La familia es la célula de la sociedad no solo por su capacidad procreadora sino por la función humanizadora del ser que procrea. En la familia se forjan personas seguras de sí mismas, que se saben queridas y protegidas; personas conscientes de su dignidad y de la dignidad de los demás; personas capaces de amar, de tomar las riendas de su vida y fundar a su vez una familia; personas, en definitiva, capaces de humanizar a la sociedad. (pág. 246)

Por lo expuesto podemos afirmar que la familia $y$ el matrimonio tienen un rol protagónico dentro de la sociedad, dado que son responsables de la formación y humanización de los hombres que conforman la sociedad en que vivimos.

Al mismo tiempo, M. Lacalle reafirma a la familia de fundación matrimonial como la responsable de proporcionar el orden y sentido a las relaciones afectivo-sexuales de los adultos; además reconoce a la familia como el entorno ideal para el crecimiento y educación de los más jóvenes, responsable de la base relacional sobre la que se desarrolla una sociedad libre y próspera. Finalmente M. Lacalle (2015) concluye “Lo cierto es que la familia tiene una dimensión pública clarísima: todo lo que ocurre en la familia tiene un reflejo en la sociedad, para bien o para mal" (pág. 234).

a) Importancia de la familia para la sociedad

La familia como piedra angular de la sociedad, juega un papel muy importante en el desarrollo de la misma. M. Lacalle (2015), hace referencia a la importancia de la familia en la solución de los principales problemas que aquejan a la sociedad de hoy, menciona además, que solo desde un fortalecimiento de la familia podremos hacer cara a problemas sociales como la drogadicción, el desempleo, la pobreza y exclusión social, enfermedades, minusvalías, por mencionar algunos. M. Lacalle (2015) resalta también que:

No es posible construir una sociedad justa, ni lograr el progreso social sin la familia, sin los lazos internos y naturales que se establecen en la familia. No es posible construir una sociedad buena sin la escuela personal y social que es la familia. (pág. 235)

Por otra parte, F. Pliego, publicó en marzo de 2012 los resultados obtenidos de su investigación acerca de la relación que existe entre los distintos "tipos" de familia y el bienestar de la población, se analizaron 351 publicaciones de estudios realizados en 13 países, entre los que se encuentra Perú. Al concluir la investigación F. Pliego señala que los distintos tipos de familia contribuyen de manera muy diferente en el bienestar de los niños y adultos:

En $84.9 \%$ de los registros de información estadística y censal obtenidos de la literatura analizada (en total se capturaron 3,318 registros), se observó que las personas casadas 
y los niños que viven con su dos padres biológicos presentan niveles de bienestar significativamente mayores. En esta estructura familiar ocurre menos violencia contra las mujeres y los hijos; los indicadores de salud física son mejores; las enfermedades mentales suceden en menor medida; los ingresos son mayores y el empleo más frecuente; las condiciones de vivienda más favorables; hay más cooperación en las relaciones de pareja; los vínculos entre padres e hijos son más positivos; el consumo de drogas, alcohol y tabaco se presentan en cantidades menores; la conducta social de los hijos es más cooperativa y cometen menos actos delictivos y el desempeño escolar de los menores de edad es mejor. (Pliego, 2012, pág. 333).

Por su parte M. Lacalle (2015) afirma:

Cuando la familia falla, la sociedad se viene abajo. Por eso las crisis familiares son siempre crisis sociales, pues todo depende de la solidez de los lazos humanos creados en la familia y de los valores transmitidos. Cuando eso no funciona nada funciona. (pág. 246)

M. Lacalle (2015) también resalta la importancia de contar con familias sólidas y auténticas comunidades de vida y amor, que permitan una renovación de las personas y por consecuencia lógica de la sociedad. Afirma también que la familia es el instrumento más eficaz para la humanización y personalización del mundo. Sin bien admite que no hay familia perfecta reconoce la importancia de la familia como el hábitat donde el ser humano, nace, crece y muere como persona humana rodeado de un amor incondicional, es por esto que reconoce a la familia como el lugar privilegiado para la socialización del individuo.

Juan Pablo II en su exhortación apostólica Familiaris Consortio (1981) reconoce que "de la familia nacen los ciudadanos, y estos encuentran en ella la primera escuela de esas virtudes sociales, que son el alma de la vida y del desarrollo de la sociedad misma" (pág. 42). Así mismo hace referencia a la importancia de la comunión y participación que se vive de manera cotidiana en los hogares en momentos de alegría o de dificultad que sirve como experiencias para la inserción de los hijos en la sociedad de manera correcta y fecunda (Juan Pablo II, 1981).

Juan Pablo II (1981) reconoce también a la familia como la primera escuela de las virtudes sociales que deben ser inculcadas por los padres a los hijos en una ambiente familiar animado por el amor. Así mismo resalta la importancia de que todos los miembros de la familia, cada uno según sus propias cualidades y virtudes tiene la responsabilidad y la gracia de construir la comunión de las personas haciendo de la familia una escuela de humanidad más completa y más rica (Juan Pablo II, 1981).

Por otro lado, C. Montoro menciona la capacidad educadora y transmisora de valores de la familia, además la reconoce como institución fundamental para el desarrollo integral de las personas, "la familia tiene un papel indiscutible en el modo en que los individuos se integran en la vida social, ya que transmite los modelos sociales y, con ellos, pautas de conducta y de relación social" (Montoro \& Barrios, 2008, pág. 54).

Así mismo, Pablo VI, en su declaración Gravssimum Educationis, resalta el rol fundamental de los padres como primeros y principales responsables de la educación de los hijos, haciendo especial énfasis en la dificultad de suplir esta función cuando es ausente. Los Padres están obligados a formar un ambiente familiar basado en el amor que favorezca la formación integra, personal y social de los hijos. Su santidad señala que "La familia es, por tanto, la primera escuela de las virtudes sociales, de las que todas las sociedades necesitan" (Pablo IV, 1965, pág. 3). 
Juan Pablo II también califica como esencial el deber y derecho educativo de los padres para con sus hijos, relacionándolo con la transmisión de la vida humana. Este deber y derecho es original y primario, está íntimamente ligado por la unión de amor que subsiste entre padres e hijos y es además insustituible e inalienable, por lo tanto no puede ser delegado o usurpado por un tercero. Juan Pablo II menciona también que además de estas características el amor paternal encuentra su realización en la acción educativa de sus hijos

No puede olvidarse que el elemento más radical, que determina el deber educativo de los padres, es el amor paterno y materno que encuentra en la acción educativa su realización, al hacer pleno y perfecto el servicio a la vida. El amor de los padres se transforma de fuente en alma, y por consiguiente, en norma, que inspira y guía toda la acción educativa concreta, enriqueciéndola con los valores de dulzura, constancia, bondad, servicio, desinterés, espíritu de sacrificio, que son el fruto más precioso del amor. (Juan Pablo II, 1981, pág. 36)

C. Conen (2012) manifiesta que "La razón por la cual la familia matrimonial es una realidad de interés público, radica en el cumplimiento de la familia de fundación matrimonial, de funciones sociales estratégicas sin las cuales ninguna sociedad resulta viable" (pág. 59).

Finalmente Juan Pablo II, resalta la importancia de la familia para toda gran sociedad.

La familia es ya, en sí misma una pequeña sociedad, de la que depende la existencia de toda grande sociedad: nación, Estado, Iglesia. Se comprende que ésta grande sociedad trate de vigilar su porvenir a través de la familia. Esta es la institución elemental que está a la base de la existencia humana. (Wojtyla, 1978, pág. 110)

b) El matrimonio como fundamento de la familia

El matrimonio es la institución natural formada por la unión libre y voluntaria entre un hombre y una mujer, que tiene como características esenciales, la unidad o donación mutua y reciproca de ambos conyugues, la indisolubilidad porque es un compromiso de amor conyugal para toda la vida, y de apertura a la vida, siendo los hijos la manifestación más perfecta del amor de los conyugues.

Juan Pablo II (1981), se refiere al amor conyugal como un don que conduce a los esposos al conocimiento mutuo de sí mismos y los convierte en una sola carne, este amor, al ser un amor de donación, no se agota en la pareja, por el contrario se fortalece en la máxima donación que se manifiesta en el amor por los hijos. Incluso cuando la procreación no es posible, no se pierde el valor de la vida conyugal, por el contrario, los esposos pueden encontrar en esta difícil situación, una oportunidad para otros servicios importantes a la sociedad, tal es el caso de la adopción y otras tantas formas de ayuda solidaria y educativa.

J. Escrivá (2015) describe al matrimonio y derecho natural a casarse; como realidades naturales, consustanciales con la propia naturaleza humana, afirma además que cada hombre por el hecho de ser tal, es portador de una tendencia al matrimonio, que tiene su fundamento en la complementariedad entre varón y mujer, la misma que se concreta en el matrimonio.

J. Escrivá (2015) añade:

El origen de la familia está más allá de cualquier ideología o debate. Se basa en un 
hecho natural que nos remonta al Creador: La diferencia sexual varón/mujer. El hombre no es un ser abstracto; se encarna necesariamente en uno de esos dos modos humanos de ser. Esa diferencia apunta -también de un modo natural y sin elucubraciones- a un doble fin: La complementariedad sexual y afectiva; y la promoción de la vida, la procreación. ¿Qué supone esto? Que la familia de fundación matrimonial hace justicia a las exigencias primarias de la persona $y$, en definitiva, a la verdad sobre el hombre. La protección social y legal que, durante siglos, ha tutelado a la familia matrimonial, no es, pues, un artificio. Al cuidar de la familia así concebida, las leyes y las costumbres defienden un bien social fundamental. (pág. 74)

Con lo expresado en el texto anterior J. Escrivá plasma de manera categórica la complementariedad sexual y afectiva así como la apertura a la vida, necesarias para establecer el vínculo matrimonial, además recuerda la importancia de proteger a la familia de fundación matrimonial en bien de la sociedad.

M. Lacalle (2015), también define el vínculo matrimonial como fundamento de la familia: "El hombre y la mujer al entregarse y recibirse recíprocamente por medio de la alianza conyugal, establecen entre sí un vínculo íntimo, profundo y duradero fundamento de la familia" (pág. 235).

Por su parte, C. Conen (2012) menciona que: "La función esencial del matrimonio es generar los niveles más profundos de encuentros íntimos entre un hombre y una mujer que incluye la apertura a la procreación, para enriquecerse y enriquecer a los hijos con su diversidad complementaria" (pág. 28).

Juan Pablo II (1981), se refiere también, en su exhortación apostólica "Familiaris Consortio" a la sexualidad como el acto de donación mediante el cual los esposos se entregan mutuamente como parte integral del amor conyugal, por el que se comprometen totalmente entre si hasta la muerte. En esta donación física total está presente toda la persona, incluso en su dimensión temporal (hasta la muerte), si alguno de los esposos se reserva algo o contempla la posibilidad de decidir de otra manera en el futuro, entonces ya no se trataría de una donación total. Está exigencia de totalidad, del amor conyugal, está relacionada también con la procreación, orientada a engendrar una persona humana, lo cual supera el orden puramente biológico y toca una serie de valores personales, que requieren para su mejor desarrollo la contribución permanente y armoniosa de los padres.

Al mismo tiempo, Juan Pablo II, menciona que:

La comunión primera es la que se instaura y se desarrolla entre los cónyuges; en virtud del pacto de amor conyugal, el hombre y la mujer «no son ya dos, sino una sola carne» y están llamados a crecer continuamente en su comunión a través de la fidelidad cotidiana a la promesa matrimonial de la recíproca donación total. (pág. 19)

Así mismo, resalta las raíces de la comunión conyugal, basadas en el complemento natural que existe entre hombre y mujer, y como ésta comunión se alimenta de la voluntad personal de los esposos de compartir su proyecto de vida, como una exigencia profundamente humana (Juan Pablo II, 1981).

Finalmente, Juan Pablo II se refiere a la unidad e indisolubilidad del matrimonio, basado en la donación mutua y total de los cónyuges.

La comunión conyugal se caracteriza no sólo por su unidad, sino también por su indisolubilidad: «Esta unión íntima, en cuanto donación mutua de dos personas, lo mismo 
que el bien de los hijos, exigen la plena fidelidad de los cónyuges y reclaman su indisoluble unidad». (Juan Pablo II, 1981, pág. 20)

El análisis precedente, nos permite afirmar que el matrimonio es una institución natural, sobre el que se fundamenta la familia. La complementariedad, indisolubilidad y donación total que exige el amor conyugal constituye la base esencial para el crecimiento y desarrollo de los cónyuges y los hijos fruto o expresión máxima de ese vínculo matrimonial basado en el amor.

\section{Conclusiones}

La importancia de la familia como hábitat natural de la persona humana, se basa en la necesidad del ser humano de crecer $y$ desarrollarse en un ambiente adecuado que le permita lograr su máximo crecimiento. En este sentido, la familia constituye el primer lugar que sirve al hombre como refugio, donde se siente protegido, amado, valorado y se identifica como persona humana, aprende a relacionarse, y a formar una idea de su propia identidad en función a los mensajes que recibe de los seres que lo rodean. Es así que la familia tiene la misión de constituirse en una verdadera comunidad de vida y amor, que brinde los medios necesarios para el desarrollo integral del ser humano.

La familia de fundación matrimonial se constituye como la base fundamental de una auténtica ecología humana. Es importante asegurar los medios y condiciones necesarios para su preservación y conservación, dadas las siguientes consideraciones:

La familia es el hábitat natural donde la persona, nace, crece, vive y muere como persona.
La familia es la primera escuela de socialización, donde el ser humano aprende a relacionarse con sus semejantes, un ser humano que ha sido criado en un ambiente de respeto $y$ amor aprende a respetar, amar y valorar a sus semejantes de manera desinteresada.

Los estudios realizados demuestran que las familias de fundación matrimonial presentan ambientes con niveles de bienestar, para sus miembros, significativamente mejores en comparación con otros "tipos" de familia.

La familia desempeña funciones sociales estratégicas, dado que es la primera escuela de formación y humanización de los hombres, sin las cuales ninguna sociedad resulta viable.

La familia es capaz de afrontar las situaciones más adversas, levantar al hombre y recordarle su dignidad personal e insertarlo nuevamente en la sociedad reconociendo su unicidad e irrepetibilidad (Juan Pablo II, 1981).

La familia tiene un papel preponderante en la solución de los principales problemas que aquejan a la sociedad. En este sentido, se hace evidente y necesaria la preservación, conservación así como el fortalecimiento de la familia a fin de hacer frente a dichos problemas sociales (drogadicción, desempleo, pobreza, desviaciones conductuales, falta de respeto por la vida, entre otros). El papel que juega la familia en el desarrollo de la sociedad resulta indispensable, no es posible tener una sociedad buena sin la escuela personal y social que es la familia (Lacalle, 2015).

La familia es el ambiente natural de humanización y personalización de la sociedad, y participa directamente de manera original y profunda en la construcción del mundo, haciendo posible una vida propiamente humana, 
en particular custodiando y transmitiendo las virtudes y los valores (Juan Pablo II, 1981).

Finalmente, el Matrimonio como una realidad natural -que se da entre un hombre y una mujer, cuya riqueza está basada en su complementariedad sexual y afectiva, y en su capacidad de donarse mutuamente en una promesa de amor para toda la vida- se constituye en el cimiento sobre el que se construye una familia.

\section{Recomendaciones}

Por lo expuesto en los apartados anteriores se puede asegurar que la familia de fundación matrimonial constituye el hábitat natural necesario para el correcto desarrollo integral de la persona humana.

En este sentido es recomendable que tanto el Estado y la Sociedad así como la familia misma desde su interior, cuenten con lineamientos y políticas orientadas a la protección integral de la familia y el matrimonio.

\section{Estado y Sociedad}

Los lineamientos y políticas de Estado deben tener en consideración y estar orientadas a la protección integral de la familia y el matrimonio.

- Es importante reconocer los derechos fundamentales de la persona, pero no solo de manera individual, sino como un ser articulado dentro de un núcleo familiar.

La familia, en cuanto es y debe ser siempre comunión y comunidad de personas, encuentra en el amor la fuente y el estímulo incesante para acoger, respetar y promover a cada uno de sus miembros en la altísima dignidad de personas. (Juan Pablo II, 1981, pág. 22)

- El Estado debe favorecer positivamente y estimular la iniciativa responsable de las familias. "Así mismo, debe asegurar a las familias todas aquellas ayudas -económicas, sociales, educativas, políticas, culturales-que necesitan para afrontar de modo humano todas sus responsabilidades" (Juan Pablo II, 1981, pág. 45).

- Los padres tienen el deber y derecho irrenunciable a la educación y formación de sus hijos. El Estado tiene la obligación de facilitar esta labor, no pretendiendo bajo ninguna circunstancia, sustituir el papel fundamental de los padres.

- La mujer en la sociedad de hoy exige el reconocimiento de sus derechos, sin embargo, es también vital el reconocimiento de su función materna y familiar en relación a las demás funciones públicas o privadas, así como su desarrollo profesional. Es necesario que tales funciones y profesiones se integren de manera armoniosa (Juan Pablo II, 1981).

- Identificar acciones que permitan reducir el índice de divorcios, esto puede llevarse a cabo estableciendo programas de apoyo a las parejas en crisis, talleres de aprendizaje para llevar una relación de pareja basada en el respeto y el amor, y asumiendo plenamente el compromiso establecido para toda la vida.

- Utilizar las inmensas posibilidades de la ciencia y avances tecnológicos en favor de la persona humana en toda su verdad, en su libertad y dignidad (Juan Pablo II, 1981). 


\section{Al interior de la familia}

Los lineamientos al interior de la familia deben orientarse al fortalecimiento y protección de la familia mediante el compromiso y la acción de cada uno de sus miembros.

- Es responsabilidad de todos los miembros, cada uno según sus propias posibilidades, hacer de la familia una comunión de personas, basada en el amor y respeto; haciendo de la familia una escuela de humanidad más completa y más rica (Juan Pablo II, 1981).

- En una sociedad como la de hoy donde el compromiso y donación o entrega total está prácticamente devaluado, es importante que los padres transmitan a sus hijos, mediante la motivación, palabras y el ejemplo, la importancia de formar una familia basada en el amor incondicional como un acto de la voluntad e incluso el heroísmo que requiere aceptar el compromiso del matrimonio para toda la vida (Francisco, 2016).

- Recuperar la conciencia y primacía de los valores morales, así como comprender el sentido último y los valores fundamentales de la vida. Fomentar la educación de la conciencia moral se ha convertido en una exigencia prioritaria e irrenunciable (Juan Pablo II, 1981).

- Es responsabilidad de todos los miembros de la familia afrontar las crisis familiares, dándoles la debida importancia, con la valentía de la paciencia, el dialogo sincero, el perdón reciproco y sacrificio, a fin de evitar fracasos o rupturas irrecuperables (Francisco, 2016).

- La confianza debe ser uno de los pilares de la familia, donde cada uno de sus miembros se sienta libre de mostrar su verdadera identidad sin temor al rechazo o a ser juzgado.

Una familia donde reina una básica y cariñosa confianza, y donde siempre se vuelve a confiar a pesar de todo, permite que brote la verdadera identidad de sus miembros, y hace que espontáneamente se rechacen el engaño, la falsedad o la mentira. (Francisco, 2016, pág. 115)

Los lineamientos de ecología humanos propuestos en la presente investigación, están orientados a preservar a la familia de fundación matrimonial como el hábitat natural necesario e imprescindible para el desarrollo integral del ser humano.

\section{Bibliografía}

Libros:

BURGOS, Juan Manuel. (2012). Introducción al personalismo, Madrid: Ediciones Palabra.

BURGOS, Juan Manuel. (2003). El personalismo, Madrid: Ediciones Palabra, Segunda Edición.

CID, María. (2014). Sociedad, familia y escuela: el reto de educar. Madrid: Fundación Universidad San Pablo CEU.

CIPRIANI, Juan Luis. (2016). Carta Pastoral al Encuentro con Cristo - Reflexiones finales Plan de acción del XX Sínodo Arquidiocesano de Lima. Lima: Editorial San Pablo.

CONEN, Cristián. (2012). Ecología Humana. Buenos Aires: Editorial Dunken.

DEL CID, Alma, MÉNDEZ, Rosemary, y SANDOVAL, Franco. (2011). Investigación, 
Fundamentos y Metodología, 2a ED, México: Editorial Pearson Educación.

FLAQUER, Luis. (2000). Las políticas familiares en una perspectiva comparada. Barcelona: Editorial Fundación La Caixa.

MELENDO, Tomás. (2002). Asegurar el amor, antes y durante todo el matrimonio. Madrid: Editorial Rialp.

PLIEGO, Fernando. (2013). Tipos de Familia y Bienestar de niños y Adultos - El debate Cultural del siglo XXI, México, Universidad Nacional Autónoma de México, Primera Edición.

PLIEGO, Fernando. (2012). Familias y bienestar en sociedades democráticas, El debate cultural del siglo XXI. México: Editorial Miguel Ángel Porrúa.

RESTREPO, Luis Carlos. (1997). Ecología Humana - Una estrategia de intervención Cultural. Segunda Edición, Bogotá: Editorial San Pablo.

SCHETTINI, Patricia, y CORTAZO, Inés. (2015). Análisis de datos cualitativos en la investigación social. Procedimientos y herramientas para la interpretación de información cualitativa, Buenos Aires: Editorial de la Universidad de la Plata.

WOJTYLA, Karol. (1978). Amor y responsabilidad, estudio de moral sexual, Madrid: Editorial Razón y Fe S.A.

\section{Libros Traducidos:}

MARTEN, Gerald. (2001). Ecología Humana Conceptos Básicos Para el Desarrollo Sustentable, Traducido por David Núñez: Editorial Earthscan Publications.

\section{Artículos publicados en obras colectivas}

ÁlVAREZ, Nicolás (Ed.). (2015). Redescubrir la Familia, diagnóstico y propuestas, Madrid: Ediciones Palabra.

BERNIS, Cristina. "Ecología Humana", en REBATO, Esther., CHARLES, Susanne., BRUNETTO, Chiarelli. (eds.). (2003). Para comprender La Antropología Biológica: Evolución y Biología Humana, Pamplona: Editorial Verbo Divino, 643654.

MONTORO Carolina y BARRIOS Guillermo (dirs). (2008). Políticas familiares, Primera Edición, Pamplona: EUNSA.

\section{Obras Publicadas por Institución}

SOCIAL TRENDS INSTITUTE. (2012). El dividendo demográfico sostenible - ¿Qué tienen que ver el matrimonio y la fecundidad con la economía? Barcelona, Social Trends Institute.

SOCIAL TRENDS INSTITUTE. (2007). Matrimonio y bien común: Los diez principios de Princeton, Barcelona, Social Trends Institute.

\section{Artículos de Revistas:}

CASTILLO, Edelmira, y VÁSQUEZ, Martha. (2003). "El rigor metodológico en la investigación cualitativa", Colombia Médica, Vol. 34, N³, 164167.

\section{Recursos electrónicos:}

ABASCAL, Rosa. No es posible redefinir el concepto de familia [Ubicado el: 8.I 2015] Recuperado de http://es.catholic.net/op/articulos/43470/cat/419/ 
no-es-posible-redefinir-el-concepto-defamilia.html

ÁLVAREZ COZZI, Carlos. (2014). La familia es el hábitat natural de ecología humana y patrimonio común de la humanidad. [Ubicado el 18.I 2015]. Recuperado de http://www.forumlibertas.com/frontend/forumlib ertas/noticia.php?id_noticia $=30460$

ÁLVAREZ COZZI, Carlos. (2014). ¿Hacia un derecho internacional de género? [Ubicado el 26.I 2016]. Recuperado de http://www.forumlibertas.com/hacia-un-derechointernacional-de-genero/

BENEDICTO XVI. (2006) Homilía del Santo Padre con motivo del "V Encuentro Mundial de las Familias, Valencia, España [Ubicado el 19.II 2016] Recuperado de http://w2.vatican.va/content/benedictxvi/es/homilies/2006/documents/hf_benxvi_hom_20060709_valencia.html

CATECISMO IGLESIA CATÓLICA. [Ubicado el 1.VII 2016] Recuperado de http://www.vatican.va/archive/catechism_sp/p2s2 c3a7_sp.html

CÓDICO CIVIL. Ministerio de Justicia y Derechos Humanos, Lima, Décimo Sexta Edición Oficial, 2015 [Ubicado el 1.VII 2016]. Recuperado de http://spij.minjus.gob.pe/notificacion/guias/CODI GO-CIVIL.pdf

CONEN, Cristián. Ecología humana: El gran desafío del siglo XXI, [Ubicado el 28.V 2015]. Recuperado de https://gsolido.wordpress.com/2014/04/11/ecolo gia-humana-el-gran-desafio-del-sigloxxi/\#comments

CONFERENCIA EPISCOPAL PERUANA. (2014). Comunicado De Los Obispos Del Perú Sobre La
Unión Civil Entre Personas Del Mismo Sexo, [Ubicado el 14 II.2015]. Recuperado de http://www.iglesiacatolica.org.pe/cep_prensa/arc hivo_2014/desarrolloinformacion_040414.htm\#e pis1

CONSTITUCIÓN POLÍTICA DEL PERÚ - 1993. [Ubicado el 01.VII 2016]. Recuperado de http://www4.congreso.gob.pe/ntley/lmagenes/Co nstitu/Cons1993.pdf

FRANCISCO. (2016). Exhortación Apostólica Amoris Laetitia. [Ubicado el 25.VII 2017]. Recuperado de http://w2.vatican.va/content/francesco/es/apost_ exhortations/documents/papafrancesco_esortazione-ap_20160319_amorislaetitia.html

FRANCISCO. (2015). Carta Encíclica Laudato Si, [Ubicado el 26.I 2016]. Recuperado de http://w2.vatican.va/content/francesco/es/encyclic als/documents/papa-

francesco_20150524_enciclica-laudato-si.html

FRANCISCO. (2015). Encuentro con las familias, Filipinas [Ubicado el 19.II 2016]. Recuperado de http://w2.vatican.va/content/francesco/es/speech es/2015/january/documents/papa-

francesco_20150116_srilanka-filippine-incontrofamiglie.html

FRANCISCO. (2013). Exhortación Apostólica Evangelii Gaudium. [Ubicado el 15.II 2016]. Recuperado de http://w2.vatican.va/content/francesco/es/apost_ exhortations/documents/papafrancesco_esortazi oneap_20131124_evangeliigaudium.html\#_ftn6 OGARCÍA, Juan. Ecología humana, [Ubicado el 07.I 2015]. Recuperado de http://es.catholic.net/op/articulos/33534/cat/916/ ecologia-humana.html 
Guía Técnica Nacional para la estandarización del procedimiento de la Atención Integral de la gestante en la Interrupción Voluntaria por Indicación Terapéutica del Embarazo menor de 22 semanas con consentimiento informado en el marco de lo dispuesto en el artículo $119^{\circ}$ del Código - Resolución Ministerial 486 - 2014 MINSA, (2014) [Ubicado el 01.VII 2016]. Recuperado de $\mathrm{ftp}: / / \mathrm{ftp} 2 . \mathrm{minsa}$.gob.pe/normaslegales/2014/RM4 86_2014_MINSA.pdf

GÓMEZ, José H. (2012). Ecología humana del matrimonio y la familia. [Ubicado el: 10.XI 2014]. Recuperado de https://www.aciprensa.com/josegomez/laecologia-humana-del-matrimonio-y-la-familia/

INEI. Encuesta Demográfica y de Salud Familia 2015, Características Generales de las Mujeres, Cuadro 2.1 [Ubicado el 20.VII 2016] Recuperado de

https://www.inei.gob.pe/media/MenuRecursivo/p ublicaciones_digitales/Est/Lib1356/index.html

JUAN PABLO II. (1991). Carta Encíclica Centesimus Annus, [Ubicado el 20.XI 2014] Recuperado de http://w2.vatican.va/content/john-paulii/es/encyclicals/documents/hf jpii_enc_01051991_centesimus-annus.html

JUAN PABLO II. (1994). Carta a las Familias, [Ubicado el 20.XII 2014]. Recuperado de http://www.vatican.va/holy_father/john_paul_ii/le tters/1994/documents/hf_jpii_let_02021994_fami lies_sp.html

JUAN PABLO II. (1981). Exhortación Apostólica Familiaris Consortio, [Ubicado el 25.XI 2015]. Recuperado de http://w2.vatican.va/content/john-paulii/es/apost_exhortations/documents/hf_jpii_exh_19811122_familiaris-
JAYABALAN, Kishore. (2014). Comprender la ecología de la persona y su entorno. [Ubicado el: 01.VII 2016]. Recuperado de http://www.univforum.org/en/node/1194

LEÓN, Nicolás. (2014). Avancemos hacia una Ecología Humana. [Ubicado el 15.1 2015]. Recuperado de https://www.df.cl/noticias/opinion/columnistas/av ancemos-hacia-una-ecologia-humana/2014-1205/212127.html

MAZZA, Ricardo. (2006). El relativismo moral y de la verdad misma. Panel: El relativismo moral como avanzada de la disgregación social. La necesidad de reconstruir un accionar conforme al Orden Natural y la Fe. II Congreso Internacional por la Familia y la Vida. Buenos Aires. [Ubicado el 15.XII 2014]. Recuperado de http://es.catholic.net/op/articulos/9136/elrelativismo-moral-y-de-la-verdad-misma.html

NACIONES UNIDAS. (1966). Pacto Internacional de Derechos Económicos, Sociales y Culturales. [Ubicado el: 14.II 2016]. Recuperado de http://www.ohchr.org/SP/Professionallnterest/Pag es/CESCR.aspx

NACIONES UNIDAS. (1948). Declaración Universal de los Derechos Humanos. [Ubicado el 05.IX 2017]. Recuperado de http://www.un.org/es/universal-declarationhuman-rights/

NOREÑA, Ana., ALCARAZ-MORENO, Noemí., ROJAS, Juan., y REBOLLEDO-MALPICA, Dinora. (2012). Aplicabilidad de los criterios de rigor y éticos en la investigación cualitativa. [Ubicado el 11.IX 2017]. Recuperado de http://www.scielo.org.co/pdf/aqui/v12n3/v12n3a 06 
Proyecto de ley $\mathrm{N}^{\circ}$ 3839/2014-IC. (2014). Proyecto de Ley que despenaliza el aborto en los casos de embarazos a consecuencia de una violación sexual, inseminación artificial $o$ transferencia de óvulos no consentidos. [Ubicado el 01.VII 2016]. Recuperado de http://enfoquederecho.com/wp3/wpcontent/uploads/2015/11/Proyecto-de-Ley-quedespenaliza-aborto-por-violaci\%C3\%B3n.pdf

Proyecto de ley $\mathrm{N}^{\circ}$ 2647-2013-CR. (2013). [Ubicado el 01.VII 2016]. Recuperado de http://www2.congreso.gob.pe/Sicr/TraDocEstProc /Contdoc02_2011_2.nsf/d99575da99ebfbe30525 6f2e006d1 cf0/588055827c08debd05257be4005 f45ec/\$FILE/PL02647120913.pdf

PABLO VI. (1965). Declaración Gravissimun Educationis Sobre la Educación Cristiana, [Ubicado el 20.VI 2016]. Recuperado de http://www.vatican.va/archive/hist_councils/ii_vat ican_council/documents/vatii_decl_19651028_gravissimumeducationis_sp.html
PÉREZ-SOBA, Juan. (2013). La ecología humana en Benedicto XVI. [Ubicado el $5 . I$ 2015]. Recuperado de http://familiayvidacadizyceuta.blogspot.com/201 3/02/la-ecologia-humana-en-benedictoxvi.html\#more

SÍNODO DE LOS OBISPOS. (2014). Los Desafíos Pastorales de la familia en el contexto de la evangelización, III Asamblea General Extraordinaria, Relatio Synodi. [ubicado el 04.XII 2015]. Recuperado de http://www.vatican.va/roman_curia/synod/docum ents/rc_synod_doc_20141018_relatio-synodifamilia_sp.html 